\title{
The match-play activity cycles in elite U17, U21 and senior hurling competitive games
}

\author{
Damien Young \\ Technological University of the Shannon, damien.young@hotmail.com \\ Kieran Collins \\ Technological University Dublin, kieran.collins@tudublin.ie \\ Laurent Mourot \\ Bourgogne Franche-Comté University
}

See next page for additional authors

Follow this and additional works at: https://arrow.tudublin.ie/ittsciart

Part of the Sports Sciences Commons

\section{Recommended Citation}

Young, D., Collins, K., Mourot, L. et al. The match-play activity cycles in elite U17, U21 and senior hurling competitive games. Sport Sci Health 15, 351-359 (2019). DOI: 10.1007/s11332-018-00523-z

This Article is brought to you for free and open access by the School of Science and Computing at ARROW@TU Dublin. It has been accepted for inclusion in Articles by an authorized administrator of ARROW@TU Dublin. For more information, please contact arrow.admin@tudublin.ie, aisling.coyne@tudublin.ie, gerard.connolly@tudublin.ie.

Funder: French Ministry of National Education, of Research and of Technology; Tomsk Polytechnic University

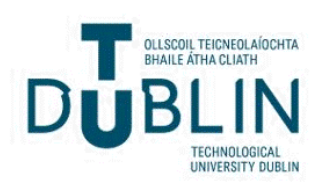


Authors

Damien Young, Kieran Collins, Laurent Mourot, and Giuseppe Coratella

This article is available at ARROW@TU Dublin: https://arrow.tudublin.ie/ittsciart/102 
See discussions, stats, and author profiles for this publication at: https://www.researchgate.net/publication/330586066

\section{The match-play activity cycles in elite U17, U21 and senior hurling competitive games}

Article in Sport Sciences for Health · August 2019

DOI: 10.1007/511332-018-00523-z

\section{CITATIONS}

4 authors:

Damien Young

Technological University of the Shannon: Midlands Midwest

21 PUBLICATIONS 131 CITATIONS

SEE PROFILE

Laurent Mourot

University Bourgogne Franche-Comté

171 PUBLICATIONS 2,633 CITATIONS

SEE PROFILE
635

Technological University Dublin - Tallaght Campus

129 PUBLICATIONS 1,861 CITATIONS

SEE PROFILE

Giuseppe Coratella

Università degli Studi di MIlano

105 PUBLICATIONS 1,112 CITATIONS

SEE PROFILE

Some of the authors of this publication are also working on these related projects:

COPD management View project

Circadian Rhythm of Heart Hemodynamic and Autonomic Variables View project 


\title{
The match-play activity cycles in elite U17, U21 and senior hurling competitive games
}

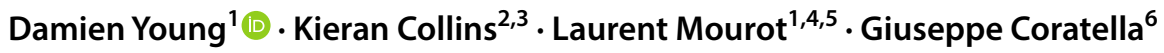

Received: 18 October 2018 / Accepted: 26 December 2018

(c) Springer-Verlag Italia S.r.l., part of Springer Nature 2019

\begin{abstract}
Purpose The current study aimed to investigate the ball-in-play (BIP) and ball-out-of-play (BOP) differences between U17, U21 and senior hurling matches.

Methods Video recordings of matches $(n=36)$ were coded and analysed for BIP and BOP. Time when the ball was continuously in-play was considered BIP, whereas any stoppages were considered BOP.

Results The total and mean BIP cycle duration showed no difference between levels. The number of BIP cycles were higher in senior matches compared to U17 ( $\mathrm{ES}=1.80$ : large) and U21 ( $\mathrm{ES}=1.27$ : large). U17 matches had a lower frequency of BIP cycles between 16 and $30 \mathrm{~s}(\mathrm{ES}=-1.75$ : large) compared to senior. Total BOP duration was longer in senior (45:30 $\pm 4: 13 \mathrm{~min})$ matches compared to $\mathrm{U} 17(36: 31 \pm 2: 30 \mathrm{~min}, \mathrm{ES}=2.59$ : very large) and $\mathrm{U} 21(36: 48 \pm 2: 53 \mathrm{~min}$, $\mathrm{ES}=2.40$ : very large). Senior matches had a longer BOP duration and greater number of BOP cycles than $\mathrm{U} 17$ ( $\mathrm{ES}=0.17$ : trivial, $\mathrm{ES}=2.20$ : very large, respectively) and $\mathrm{U} 21(\mathrm{ES}=0.17$ : trivial, $\mathrm{ES}=0.99$ : moderate, respectively). $\mathrm{U} 17$ matches had a lower frequency of BOP cycles $>60 \mathrm{~s}(\mathrm{ES}=-1.33$ : large) compared to senior.

Conclusion Although there was a difference in the total match duration, U17 and U21 matches have similar BIP time as seniors, suggesting that U17 and U21 players should be conditioned to withstand the elite senior BIP duration. In training practice, high-intensity short-duration games are suggested for repeating the duration demands of competition.
\end{abstract}

Keywords Physical demands · Time-motion analysis $\cdot$ Team sport $\cdot$ Worst case scenario $\cdot$ Ball-in-play-ball-out-of-play ratio

Damien Young

damien.young@hotmail.com

1 Research Unit EA3920 Prognostic Markers and Regulatory Factors of Cardiovascular Diseases and Exercise Performance, Exercise Performance Health, Innovation Platform, Univ. Bourgogne Franche-Comté, Besançon, France

2 Gaelic Sports Research Centre, Institute of Technology Tallaght, Dublin 24, Tallaght, Ireland

3 The Tom Reilly Building, Research Institute for Sport and Exercise Sciences, Liverpool John Moores University, Henry Cotton Campus, 15-21 Webster Street, L3 2ET Liverpool, UK

4 EA3920 Prognostic Factors and Regulatory Factors of Cardiac and Vascular Pathologies, (Exercise Performance Health Innovation -EPHI), Univ. Bourgogne Franche-Comté, 25000 Besançon, France

5 Tomsk Polytechnic University, Tomsk, Russia

6 Department of Biomedical Sciences for Health, University of Milan, Milan, Italy

\section{Introduction}

Hurling is an Irish 15 -a-side intermittent stick and ball invasion team sport played on a pitch which is $140 \mathrm{~m}$ long and $90 \mathrm{~m}$ wide [1]. It is a physically demanding and highly skilful game with periods of high-intensity efforts similar to other team sports [1-6]. A typical senior hurling match (70 $\mathrm{min}$ ) is $10 \mathrm{~min}$ longer compared to U17 [7] and U21 [3] $(60 \mathrm{~min})$ levels. There is a single half-time period of $15 \mathrm{~min}$ and $10 \mathrm{~min}$ after $35 \mathrm{~min}$ and $30 \mathrm{~min}$ for seniors and U17/U21, respectively. The best players at sub-elite (club) level are selected to represent their elite (inter-county) team from U14 to senior level. However, U17, U21 and senior hurlers are the only elite levels which compete for a Provincial and All-Ireland hurling Championships [8]. The aim of the game is to outscore the opposition team, one point (point) and three points (goal) are awarded for successfully striking the ball through the opposition goalposts over or under the crossbar, respectively. A high degree of hand-eye 
coordination is required to perform hurling-specific skills such as catching the ball in the air, balancing the ball on the hurley, striking the ball long distances $(>80 \mathrm{~m})$ while being tackled by opposing players [9]. As the ball can travel large distances $(>80 \mathrm{~m})$ between attack and defense frequently, players can end up being active quite suddenly to contest for possession [1]. Video analysis research in elite senior hurling showed that the three most important skills were lifting the ball from the ground to gain possession, running four steps while in possession and striking the ball from the hand [10]. These skills illustrate that players gain and release possession regularly [11]. However, limited studies exist that quantify the match-play physical demands of hurling [1-3, 7, 12-14].

Although time-motion analysis has been used to quantify the physical demands in team sports [15-18], GPS has been the most popular method of choice in hurling $[1-3,12,13$, 19]. The game of hurling is physically demanding with highintensity running performances (e.g. high-speed running and sprinting) interspersed with periods of low-intensity activity (e.g. walking and jogging) $[1-3,12,13]$. Greater running performances are observed for elite seniors $[2,14]$ compared to sub-elite seniors [1], U21 [3] and U17 [7] hurlers [1-3, $12,13]$. However, when the relative distance is compared between competition levels, elite seniors covered a similar relative distance to U21s [3] and U17s [7] but not sub-elite seniors [1]. It seems that elite level competition requires higher running performances. To inform the training process and ensure that players are adequately prepared for competition, knowledge of the game demands are necessary. Currently, there are a limited number of research papers that describe the match-play running demands in hurling [1, $3,7,13,14]$ there are no data available that describe the duration demands of competition between playing levels. Thus, the further quantification of the match-play duration demands would provide a clearer understanding of the game requirements and if a gap between levels exists. With this information, conditioning coaches could plan and implement training activities [20-24] that replicate these competition demands.

Another method that has been used to provide an insight into the physical demands of team sports is the examination of the ball-in-play (BIP) periods $[12,15,16,25,26]$. The total game duration is a poor indicator of the actual matchplaying time, as the ball was only in-play for $41 \%$ of the overall match time in senior hurling [12], 63\% in Rugby League [15], and 44\% in International Rugby Union [27]. Consequently, the match-play demands which include the ball-out-play (BOP) stoppage duration may underestimate the true intensity of competition [26]. In addition, this BIP time is accumulated from short activity periods interspersed with varying lengths of BOP [17]. It is suggested that analysing these BOP cycles can provide a more appropriate description of the structure of an intermittent game [17]. In soccer, results show that games were interrupted for almost $38 \%$ of the total match time with $\approx 108$ stoppages (e.g. goal kicks and throw-ins) per match [17]. A similar number of stoppages was reported in senior hurling with the mean BIP time between interruptions lasting $\approx 19 \mathrm{~s} \mathrm{[12].} \mathrm{There-}$ fore, conditioning programs based on the total match-play demands could result in players being underprepared for the most demanding passages of play [26].

Although BIP and BOP times were described in senior hurling [12] and greater running performances are reported between U21 [3] and senior [2, 14] levels using GPS, no data currently exist for the BIP and BOP durations between levels. Furthermore, no BIP and BOP (number of cycles, duration, and type of BOP stoppage) data are available at $\mathrm{U} 17$ and $\mathrm{U} 21$ competitions, not even a direct comparison between levels has been performed. Research that quantifies the differences in BIP and BOP of each competition would provide a better understanding of a potential gap between levels and further aid the development of game-specific activities [16]. In addition, conditioning players to undertake the physical demands of competition should include the "worst-case scenario" passages of play [13]. However, no data exist to quantify these worst-case time durations of play at U17, U21 and senior level. Therefore, the current study aimed to quantify BIP/BOP data at each level and examine the differences in the number and duration of BIP cycles and the number, type and duration of BOP cycles between U17, U21 and senior competitions. It was hypothesised that meaningful differences would exist among playing levels for the duration and number of BIP cycles and the number, type and duration of BOP cycles.

\section{Methods}

\section{Design}

The BIP and BOP durations of U17, U21 and senior hurling championship matches $(n=36)$ were investigated using a prospective case series experimental design. These championship games are the highest level of competition that players can represent their county at. Video footage was taken from the main camera of the stadium, placed about $30 \mathrm{~m}$ above the pitch [17]. Matches (U21 and seniors) were selected if they were broadcast on TV and freely available in the public domain [16]. However, only highlights of the U17 matches were broadcasted on TV, so a request was made to the TV Company (TG4) for access to the full duration of each match, which were provided on DVDs. Video footage was coded for BIP and BOP. The time when the ball was within the playing area and available for players to gain possession was considered BIP, whereas any stoppages during 
the match were considered as BOP. Each stoppage to the match was classified by different variables. These variables included the type of observation that interrupted play (shot at goal, free, free attempted, sideline or throw-in) (definitions in Table 1) and the duration of the interruption.

\section{Participants}

Five hundred thirty-eight male elite hurlers were involved in the current study. All players in the current study were competing at the highest level (Provincial and All-Ireland Championships) and were selected as they were members of their counties' squad that season (2017-2018). The subjects were categorised as U17 $(n=124), \mathrm{U} 21(n=197)$ and senior $(n=217)$. A total of seven, eight and nine different teams were used for U17, U21 and senior, respectively. Video footage of matches played over two playing seasons (2017-2018) within the elite U17 $(n=12)$, U21 $(n=12)$ and senior $(n=12)$ hurling championship was used in this study. The local Institution's Ethics Committee approved all procedures, and the study was conducted according to the Declaration of Helsinki (1975) for studies involving human subjects.

\section{Procedures}

Video recordings for 36 championship matches, played over two competitive seasons (2017-2018), resulting in a total of 3048 BIP and 2976 BOP cycles were analysed. Video footage was coded by an experienced observer $(>100 \mathrm{~h}$ observation time) for BIP and BOP using SportsCode video analysis software (v11.2.20) (SportsCode, Sportstec, Lower Hutt, New Zealand) [27]. Time when the ball was continuously in-play was considered BIP, whereas any stoppages during the match were considered BOP. Each time the ball went out-of-play it was registered as a stoppage $[17,28]$ and classified by different variables (shot at goal, free, free attempted, sideline and throw-in) [15, 16]. Post-coding, data were analysed for the number of cycles and the duration of each cycle for both BIP and BOP. Furthermore, the longest $\mathrm{BIP}$ duration was recorded. The number and the duration of each stoppage were also analysed. In addition, a frequency distribution of BIP and BOP was determined based on the following classifications: 0-15, 16-30, 31-45, 46-60 and $>60 \mathrm{~s}$ [25]. A BIP-BOP ratio was also determined using rolling calculations of 2 sequential BIP cycles and the intervening BOP periods $[15,16]$. The intra-class correlation coefficients and typical error of measurement for the coding of BIP and BOP were 0.92 and $1.2 \%$ and 0.89 and $1.6 \%$, respectively. Common guidelines (e.g. maximum of $2 \mathrm{~h}$ for observation) to minimise observer errors when using computers were used [29].

\section{Statistical analysis}

All statistical analyses were performed using SPSS for Windows (Version 22, SPSS Inc. Chicago, IL, USA). The intra-observer reliability was assessed by coding 6 randomly selected matches. Data were analysed for the mean number and duration of BIP and BOP cycles, while the percentage of $\mathrm{BIP} / \mathrm{BOP}$ relative to the total playing time for each game was calculated. In addition, the stoppage type and mean duration were also recorded and analysed. The differences in the total, the cycle duration, the number of cycles and the frequency distributions of BIP and BOP between U17, U21 and senior were compared using a one-way ANOVA. When required, comparisons of group were required using a Bonferroni post hoc test. Standardised ES were calculated with $\leq 0.20$, $0.21-0.60,0.61-1.20,1.21-2.00$ and $2.01-4.00$ and interpreted as follows: trivial, small, moderate, large and very large differences, respectively, as recommended by Hopkins [30]. Statistical significance was set at an accepted level of $\alpha<0.05$. Data are presented as mean, standard deviation $( \pm \mathrm{SD})$ and $95 \%$ confidence intervals $(95 \% \mathrm{CI})$.

\section{Results}

The mean total match duration, the BIP and BOP duration and the number and duration of individual BIP and BOP cycles are displayed in Table 2 . The ball was in play $44 \%, 43 \%$ and $40 \%$ of the overall playing time for U17, U21 and senior matches, respectively. There was no difference $(p>0.05)$ in the average longest BIP cycle between $\mathrm{U} 17(73 \pm 14 \mathrm{~s}), \mathrm{U} 21(75 \pm 15 \mathrm{~s})$ and senior $(100 \pm 79 \mathrm{~s})$ matches. The BIP-BOP ratio was 1.00, 1.01 and 0.98 for
Table 1 Operational definitions of variables that stop the game of hurling

\begin{tabular}{ll}
\hline Action & Descriptor \\
\hline Shot at goal & Any strike that ends in a goal, point or wide \\
Free & A foul that is awarded, when taken remains in play \\
Free attempted & A foul that is awarded, when taken ends in a goal, point or wide \\
Sideline & The ball travels over the playing boundary at either side of the field \\
Throw-in & Referee stops play for an injury or when a player accidently falls \\
& near the ball and is in danger of getting struck with a hurley \\
\hline
\end{tabular}


Table 2 Duration and number of ball-in-play and ball-out-of-play activities for U17, U21 and senior hurling matches

\begin{tabular}{|c|c|c|c|c|c|c|}
\hline & U17 & $\mathrm{U} 21$ & Senior & $\begin{array}{l}\text { U17 vs U21 } \\
\text { MD, } 95 \% \text { CI, ES }\end{array}$ & $\begin{array}{l}\text { U17 vs senior } \\
\text { MD, } 95 \% \mathrm{CI}, \mathrm{ES}\end{array}$ & $\begin{array}{l}\text { U21 vs senior } \\
\text { MD, } 95 \% \text { CI, ES }\end{array}$ \\
\hline $\begin{array}{l}\text { Mean total match dura- } \\
\text { tion (min:s) }\end{array}$ & $65: 02 \pm 1: 42$ & $65: 06 \pm 3: 06$ & $76: 00 \pm 3: 44^{\mathrm{ab}}$ & $\begin{array}{l}-4,-217 \text { to }-209 \\
\mathrm{ES}=-0.03: \text { trivial }\end{array}$ & $\begin{array}{l}-658,-871 \text { to }-445 \\
\text { ES }=-3.78: \text { very } \\
\text { large }\end{array}$ & $\begin{array}{l}-654,-861 \text { to }-447 \\
\mathrm{ES}=-3.18: \text { very } \\
\text { large }\end{array}$ \\
\hline \multicolumn{7}{|l|}{ Ball-in-play } \\
\hline $\begin{array}{l}\text { Mean duration } \\
\text { (min:s) }\end{array}$ & $28: 30 \pm 3: 29$ & $28: 18 \pm 3: 05$ & $30: 30 \pm 2: 54$ & $\begin{array}{l}13,-211 \text { to } 236, \\
\mathrm{ES}=0.07: \text { trivial }\end{array}$ & $\begin{array}{l}-119,-343 \text { to } 104, \\
\mathrm{ES}=-0.62: \text { moder- } \\
\text { ate }\end{array}$ & $\begin{array}{l}-132,-349 \text { to } 85, \mathrm{ES}= \\
-0.73: \text { moderate }\end{array}$ \\
\hline Number of cycles $(n)$ & $80 \pm 5$ & $82 \pm 6$ & $89 \pm 5^{\mathrm{ab}}$ & $\begin{array}{c}-3,-9 \text { to } 4, \mathrm{ES}= \\
-0.36: \text { small }\end{array}$ & $\begin{array}{l}-9,-15 \text { to }-2.6, \text { ES } \\
=-1.80: \text { large }\end{array}$ & $\begin{array}{l}-6,-13 \text { to }-0, \mathrm{ES}= \\
-1.27: \text { large }\end{array}$ \\
\hline $\begin{array}{l}\text { Mean individual } \\
\text { cycle duration } \\
\text { (min:s) }\end{array}$ & $0: 22 \pm 0: 15$ & $0: 21 \pm 0: 15$ & $0: 22 \pm 18$ & $\begin{array}{l}1,-1 \text { to } 3, E S=0.07: \\
\text { trivial }\end{array}$ & $\begin{array}{l}1,-2 \text { to } 3, \mathrm{ES}=0.00: \\
\text { trivial }\end{array}$ & $\begin{array}{c}-1,-3 \text { to } 1, \mathrm{ES}= \\
-0.06: \text { trivial }\end{array}$ \\
\hline \multicolumn{7}{|l|}{ Ball-out-play } \\
\hline $\begin{array}{l}\text { Mean duration } \\
\text { (min:s) }\end{array}$ & $36: 31 \pm 2: 30$ & $36: 48 \pm 2: 53$ & $45: 30 \pm 4: 13^{\mathrm{ab}}$ & $\begin{array}{r}-17,-251 \text { to }-217 \\
E S=-0.10: \text { trivial }\end{array}$ & $\begin{array}{l}-539,-773 \text { to }-304 \\
\text { ES }=-2.59: \text { very } \\
\text { large }\end{array}$ & $\begin{array}{l}-522,-750 \text { to }-249 \\
\text { ES }=-2.40: \text { very } \\
\text { large }\end{array}$ \\
\hline Number of cycles $(n)$ & $78 \pm 4$ & $82 \pm 7$ & $88 \pm 5^{a b}$ & $\begin{array}{c}-3,-10 \text { to } 3, \mathrm{ES}= \\
-0.70: \text { moderate }\end{array}$ & $\begin{array}{c}-10,-16 \text { to }-4, \mathrm{ES}= \\
-2.20: \text { very large }\end{array}$ & $\begin{array}{c}-7,-13 \text { to }-0, \mathrm{ES}= \\
-0.99: \text { moderate }\end{array}$ \\
\hline $\begin{array}{l}\text { Mean individual } \\
\text { cycle duration } \\
\text { (min:s) }\end{array}$ & $0: 28 \pm 0: 21$ & $0: 28 \pm 21$ & $0: 31 \pm 0: 26^{\mathrm{ab}}$ & $\begin{array}{l}0,-3 \text { to } 3, \mathrm{ES}=0.00: \\
\text { trivial }\end{array}$ & $\begin{array}{l}-4,-7 \text { to }-1, \mathrm{ES}= \\
-0.17: \text { trivial }\end{array}$ & $\begin{array}{l}-4,-7 \text { to }-1, \mathrm{ES}= \\
-0.17: \text { trivial }\end{array}$ \\
\hline
\end{tabular}

Data are presented as total, mean $\pm \mathrm{SD}$, mean differences, $95 \% \mathrm{CI}$ and effect size

$M D$ mean difference, $95 \%$ CI 95\% confidence intervals, $E S$ effect size

${ }^{\mathrm{a}} p<0.05$ compared to $\mathrm{U} 17$

${ }^{\mathrm{b}} p<0.05$ compared to $\mathrm{U} 21$

U17, U21 and senior, respectively, with no significant difference $(p>0.05)$ between levels.

The frequency of BIP in each duration category is presented in Fig. 1a. In senior matches, there were a greater number of BIP cycles between 16 and $30 \mathrm{~s}$ compared to $\mathrm{U} 17 \mathrm{~s}(p=0.011, \mathrm{MD}-6,95 \% \mathrm{CI}-11 /-1, \mathrm{ES}=-1.75)$. There were no differences $(p>0.05)$ during any other BIP cycle between any playing levels. The frequency of BOP in each duration category is presented in Fig. 1b. Senior hurling matches had a greater number of BOP cycles $>60 \mathrm{~s}$ compared to U17 ( $p=0.009, \mathrm{MD}-5,95 \% \mathrm{CI}-9 /-1, \mathrm{ES}$ $=-1.33$, ) level.

The mean number and duration of stoppages are presented in Fig. 2. The number of shots at goal is the most frequent stoppage reason in hurling matches. However, no difference $(p>0.05)$ exists between U17, U21 and senior matches. Frees that were scored take the longest duration to restart the match in hurling but no difference $(p>0.05)$ was observed between levels. There was a longer duration spent from the time a free is awarded until it is taken in senior compared to U21 $(p=0.030, \mathrm{MD}-10,95 \% \mathrm{CI}$ $-19 /-1, \mathrm{ES}=1.64)$ matches.

\section{Discussion}

Currently, there are limited studies which describe the match-play demands of hurling, particularly between playing levels (U17-senior) [1-3, 13]. This was the first study to investigate the differences in the number and duration of BIP cycles, the number and duration of BOP cycles and the number of stoppage types between U17, U21 and senior competitions at elite level. Contrary to what was hypothesised, there was no difference between U17, U21 and senior matches for total BIP, the mean individual BIP cycle duration and number of stoppage types. In addition, there was no difference between U17 and U21 matches in any of the durations recorded. However, as hypothesised, there were differences between groups in the total match duration, total BOP and the number and mean individual BOP cycle duration, with senior matches found to have a longer duration compared to U17 and U21. With these new findings, this information can be used to inform coaches of the match-play duration demands of elite hurling where duration-specific training activities may be designed. 

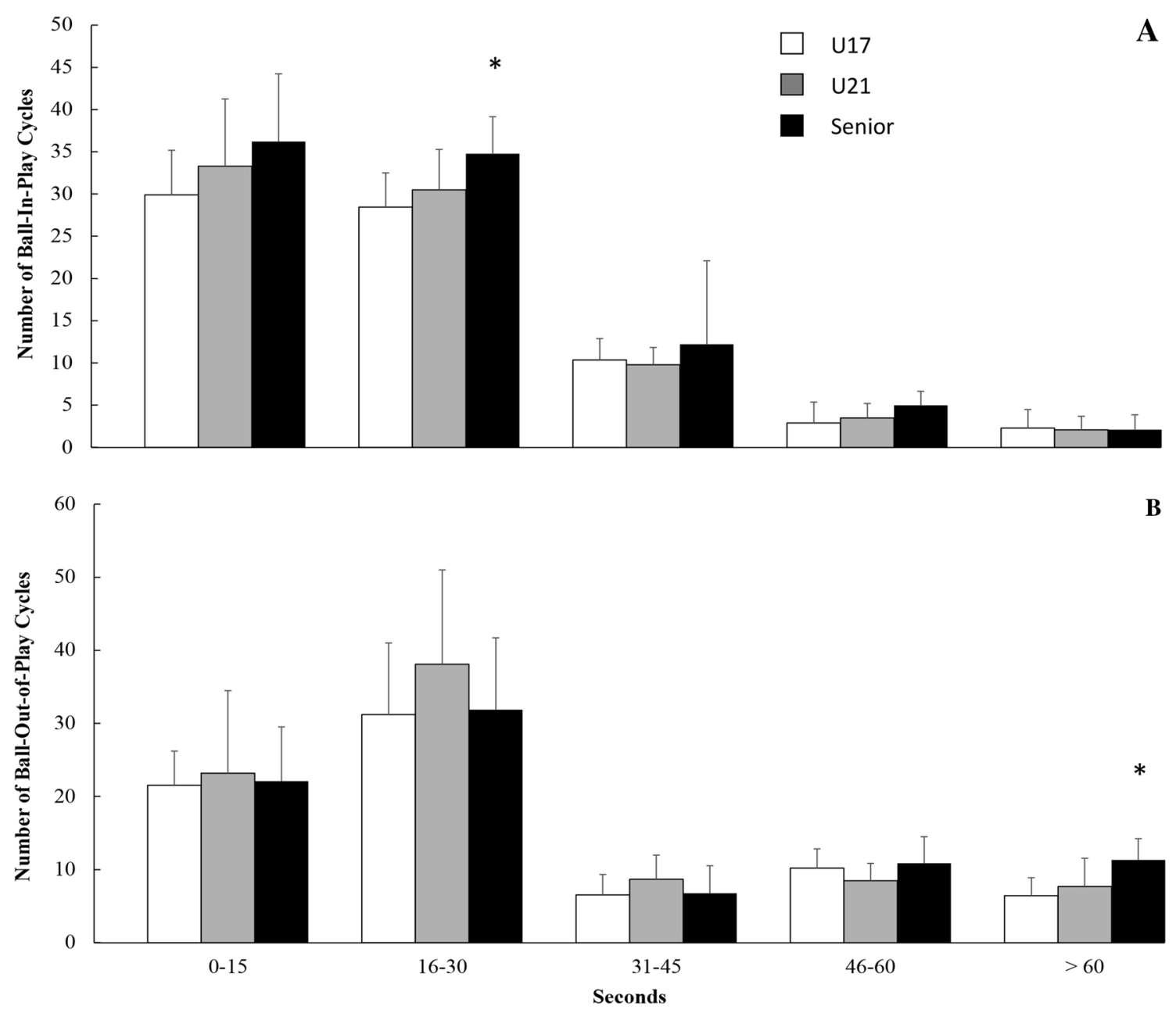

Fig. 1 Mean \pm SD number of ball-in-play (a) and ball-out-play cycles (b) in U17, U21 and senior is shown. * $p<0.05$ compared to U17

According to the official rules of hurling, the match duration for senior and U17/U21 is $70 \mathrm{~min}$ and $60 \mathrm{~min}$, respectively. However, the current results showed that the actual full match duration is $9 \%$ longer at senior and $8 \%$ longer at U17/U21 level compared to the official match time. This additional time, which is at the discretion of the referee, is added to the end of the game to account for injuries and substitutions. The current data show that each level is required to play for a longer duration than the official rules. Interestingly, there was no difference in the mean BIP time and individual BIP cycle duration between levels (U17, U21 and senior). Similar mean BIP time $(\approx 31 \mathrm{~min})$ and mean individual BIP cycle duration $(\approx 19 \mathrm{~s})$ were found in a previous senior hurling study [12]. The commonality of playing area, number of players, skills involved and methods of scoring between games may also explain how the BIP results are similar. Despite the fact that the total BIP time is similar, it must be noted that compared to U17 and U21 level, senior matches take $11 \mathrm{~min}$ longer to complete (76 min), leading to a largely greater number of BIP cycles. Furthermore, this additional time and number of cycles may highlight the higher physical demands required at senior level [2, 3, 13]. The higher number of BIP cycles suggest the need to prepare players to transition from U17/U21 to senior level. Interestingly, even though previous senior hurling [12] BIP research was published 8 years ago, similar total BIP times are recorded here. However, the comparison only includes information about the duration of BIP and fails to compare the playing actions that occur within that time, which may have changed. The most critical events (e.g. scoring) occur during periods where the ball is in play. Therefore, beginning at U17, players need to be able to perform high-intensity effort during the BIP periods to cope with these critical events.

The mean individual BIP cycle duration was similar at all levels. This supports the observation that hurling is an intermittent start-stop game, which consists of short periods of BIP [13]. Usually conditioning programs are based on the match-play demands, which are averaged across the full duration of the match. However, research which has analysed 
Fig. 2 Mean \pm SD number (a) and duration (b) of stoppages in U17, U21 and senior. ${ }^{*} p<0.05$ compared to U21
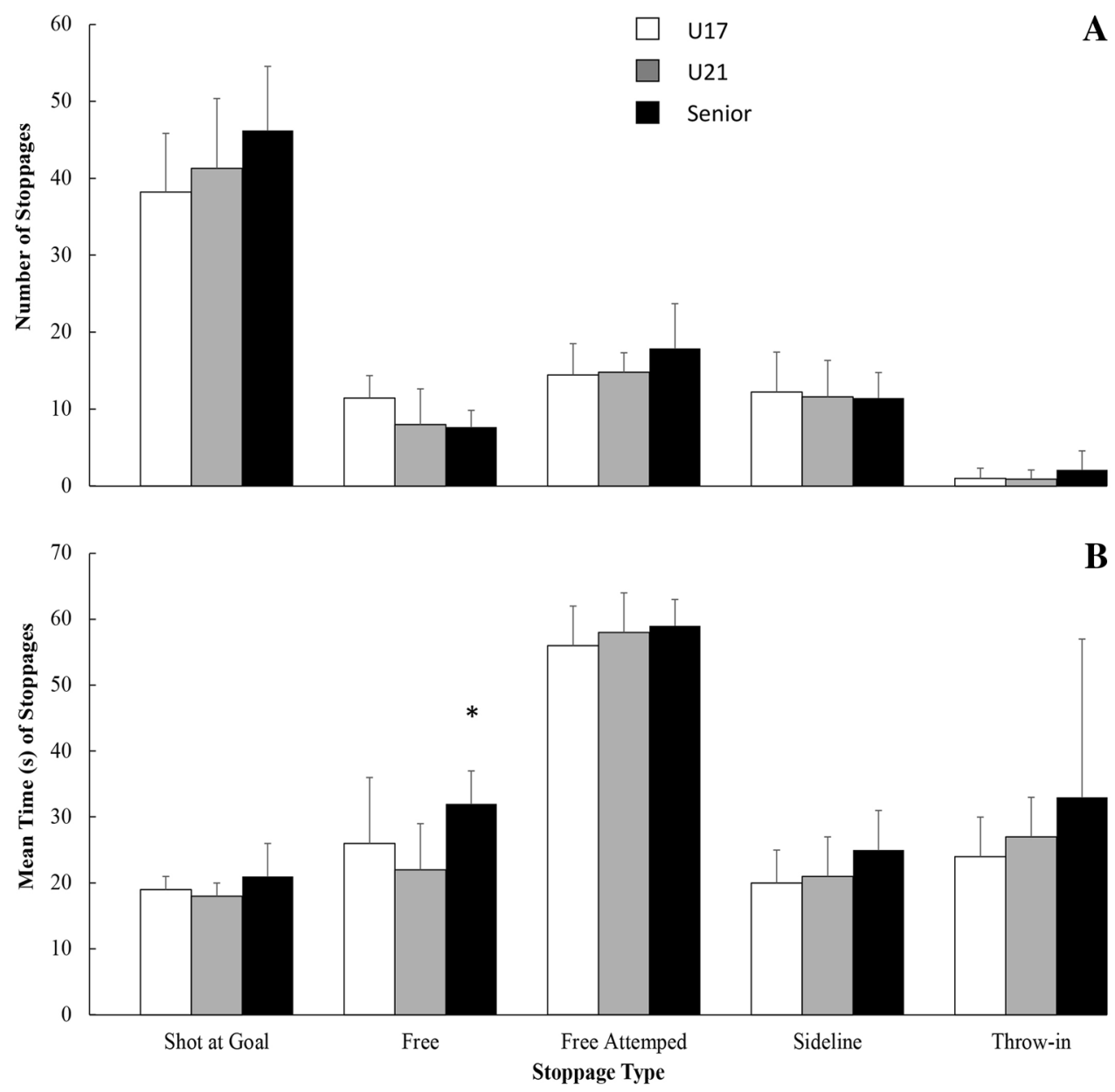

the worse-case scenario periods have provided valuable information about the maximal intensities that actually occur in competition $[13,15]$. Previous research in senior hurling investigated the maximal running intensity period of competition using a 1-min rolling average method [13]. However, the current study found that the ball was rarely in-play for longer than $46 \mathrm{~s}$. Since there was no difference in the average longest BIP cycle duration between levels, the players need to be prepared for these worst-case duration periods no matter what the playing level. Additionally, it is acknowledged that players can be active when the ball is out-of-play, but it must be considered that the worst-case scenario period for total distance, high-speed running distance and sprint distance may be even more demanding given this shorter duration.

Senior hurling matches have a very largely longer mean BOP time, moderately-to-largely greater number of BOP cycles and a trivially longer individual BOP cycle duration compared to U17 and U21. Although significant, these individual BOP cycle duration differences represented a practical difference of just $3 \mathrm{~s}$ between levels. Similar BOP cycle duration $(\approx 28 \mathrm{~s}$ ) was reported previously for senior hurling [12]. However, such data are not available for the total BOP and number of BOP cycles. As the senior matches have a $9 \%$ longer match duration (Table 2), coupled with a higher number of BOP cycles compared to U17 and U21, this additional time at senior may explain the difference between levels. In addition, as senior players know they have a longer match duration, they may have developed a pacing strategy to use the BOP duration to slow the game down and recover so they could maintain high-intensity performance [26, 31]. The current match demands are higher at senior [2, 14] compared to U21 [3], while no such data are currently available at U17. Hence, it could be argued that the senior players may use this BOP as recovery to maximise their performance during BIP time.

Analysing the game stoppages in hurling provides coaches with valuable information about the structure of the game. Furthermore, coaches could use this knowledge to design activities to practice the physical movements associated with the most frequent methods of restarting the game. No matter what the level, at least $50 \%$ of all stoppages occurred as a result of a shot at goal. This emphasises the high-frequency of attempted scores in hurling, which adds to the spectator appeal. In fact, a shot at goal from play occurred every 2 min or less no matter what the level. Previously, a strong 
relationship was shown between shot count and match outcome in hurling [11]. This places an importance on winning possession within the BIP cycle as a shot at goal occurs in more than half of the BIP cycles. Following a shot at goal or a free attempted, which is the second highest stoppage in hurling, the goalkeeper strikes the ball back into play. Therefore, as this method (puck-out) of restarting play $(n=57)$ occurs very frequently during matches, players at all levels need to be able to run back into position within this BOP time to position themselves to gain possession. There were no differences in the number of stoppages between levels. Even though there is a difference in the overall number of stoppages, in hurling when the game ends is at the discretion of the referee. The end of the game usually occurs when the ball is in play. Therefore, there was no stoppage category identified as the end-point. This may explain the difference between the stoppage type and the number of BOP cycles.

The longest mean duration of stoppage was for frees attempted. In this case, the teams' specialist free-taker who may be some distance away must move to the free location, place the ball, perform their free-taking routine and strike the ball over the bar or in some cases outside the post and wide. The goalkeeper must then get the ball and restart the game. All this time accumulates and explains why this stoppage takes time before the game can restart. Once a scorable free is awarded, players may use this time to recover and get refocused for the next BIP cycle or hydrate knowing that it will be approximately $1 \mathrm{~min}$ before the ball is back in play. The only difference in stoppage duration occurred in frees awarded. In senior matches, frees take longer to restart play compared to U21 level. Given that frees awarded can include the time for players' injuries to be treated, in the matches analysed here, this may have accounted for the longer BOP time associated with frees at senior level. In addition, the tactical formation to defend frees may be different, where the defense is more compact in senior matches. Players may take more time to select the best option available to maintain possession and wait for the space to be created before striking the free. With the overall similarities in the stoppage type and duration, it can be assumed that the tactical, technical and physical elements associated with the methods of restarting play can be initiated at U17 level and developed and used at all levels thereafter.

To gain a further understanding of the intensity and recovery periods in hurling, the BIP-BOP ratio was used $[15,16]$. This ratio was calculated by assessing two sequential BIP cycles and the intervening BOP periods $[15,16]$. The results showed a BIP-BOP ratio close to 1 with no difference between the playing levels. During BIP, highintensity efforts occur close to the ball [9]. Specifically, seniors [13] and U21 [3] hurlers have been shown to run faster than $22 \mathrm{~km} \mathrm{~h}^{-1}$ (sprints) $\approx 22$ and $\approx 18$ times, respectively, during a game. This is coupled with the number of times players perform high-speed running efforts $\left(17-22 \mathrm{~km} \mathrm{~h}^{-1}\right.$ ) to cover $\approx 759 \mathrm{~m}$ and $\approx 661 \mathrm{~m}$ distance for seniors [13] and U21s [3], respectively. These BOP periods can be used by the players to recover and facilitate the performance of these high-intensity efforts. Therefore, players should be conditioned to perform high-intensity efforts followed by a similar period of recovery.

Similar to other invasion-type games [4, 15-17, 28, 32], in hurling, there is a contest for possession with the aim of scoring. Thus, stoppages in the game are quite frequent. Describing the mean BIP and BOP cycle duration can give an overview of the match. However, further analysis which describes the number of short, medium and long BIP cycles may give a better understanding of the structure of the game [17]. Thus, in the current study, the total BIP and BOP durations were further divided to identify the frequency of durations within five time categories so that training activities could be designed accordingly $[15,16,25]$. The vast majority of individual BIP cycle duration was of a short duration with $79 \%$ and $80 \%$ of BIP cycles lasting under $30 \mathrm{~s}$ for U17/ U21 and senior matches, respectively. There were a similar number of BIP and BOP cycles across the range frequencies between the levels. The only observed differences occurred between the 16-30 s (BIP category) and $>60 \mathrm{~s}$ (BOP category), where senior matches had $20 \%$ and $36 \%$ more BIP and BOP cycles than U17s, respectively. The additional playing experience at senior compared to U17 level may have influenced the BOP duration. At senior level, players may use the BOP time to slow the game down and halt the opposition momentum, whereas U17s may be eager to get the game restarted. Therefore, it is important that players have the capacity to be able to perform multiple BIP cycles over various durations and to recover during the $\mathrm{BOP}$ periods.

The present study comes with acknowledged limitations. Only the match-play duration demands were analysed with no attempt made to measure the physical running demands. First, even though the ball is in play, the present study was not designed to measure the intensity of the players' movements. Future studies need to examine the running demands within BIP times as the match-play demands may be significantly greater than averaged over the full match duration. Second, the BOP cycle was coded as a stoppage so that coaches could be informed of how the match was interrupted and restarted. As a result, injuries were coded as for how the game was stopped. Therefore, some stoppage types may have been longer if there was an injury at that time and the referee allowed the player to be treated. Third, the current study did not account for where the ball was located on the field during the BIP cycle. The ball may have been in the same half for the duration of the BIP cycle. As a result, some players may have been involved in high-intensity activity and players at the opposite half involved in low-intensity 
movement. Future studies should consider the location of the ball and the number of ball possessions during these BIP cycles. This would help to quantify how many players are actively involved during each BIP cycle, and further indicate the intensity of each BIP cycle. Fourth, match outcome was not considered here. This may have affected the BOP time as winning teams may have tried to slow the game down towards the end of the game. Future studies should investigate how the BIP duration changes as the match progresses, how the winning or losing team in the last 10 min manages the BOP time and how the final match outcome influences BOP time. Lastly, the BIP for U17 and senior matches may be affected by the format of the championship. The condensed fixture schedule with four games played in 5 weeks may have increased players' fatigue and affected the BIP and BOP durations.

\section{Conclusions}

This was the first study to investigate the differences in the number and duration of BIP cycles, the number and duration of BOP cycles and the number of stoppage types between U17, U21 and senior competitions at elite level. The findings showed that there was no difference between U17, U21 and senior matches for total BIP, the mean individual BIP cycle duration and number of stoppage types. In addition, there was no difference between U17 and U21 matches in any of the durations recorded. However, there were differences between groups in the total match duration, total BOP and the number and mean individual BOP cycle duration, with senior matches found to have a longer duration compared to U17 and $\mathrm{U} 21$. This study provides a number of practical applications for coaches to help them prepare players for the demands of competition. The results demonstrate the requirement of players to be able to repeat short-to-moderate periods of play and recover during brief stoppages in play. Coaches should consider the range of BIP times when designing training activities so that the competition demands can be replicated. Even though the longest BIP cycles are uncommon and rarely last over $1 \mathrm{~min}$, hurlers need to experience these durations in training to be physical prepared to play continuously without a break in play. However, these results would question the use of some of the current training practices that include long ( $>5 \mathrm{~min}$ ) uninterrupted possession-style training activities as they fail to replicate the match-play duration and stoppage demands of hurling. In training practice, high-intensity short-duration games are suggested for repeating the duration demands of competition. With these new findings, this information can be used to inform coaches of the match-play duration demands of elite hurling where duration-specific training activities may be designed.
Funding The research was funded by grants from the French Ministry of National Education, of Research and of Technology (EA3920) and from Tomsk Polytechnic University Competitiveness Enhancement Program grant, Project № ВИУ-ИСГТ-108/2017-ТРU CEP-HSTI-108/2017.

\section{Compliance with ethical standards}

Conflict of interest The authors declare that they have no conflict of interest.

Ethical approval This study was approved by the University FrancheComté and the athletes were informed of the purposes and inherent risks associated with this research.

Informed consent Written informed consent was obtained.

\section{References}

1. Young D, Mourot L, Coratella G (2018) Match-play performance comparisons between elite and sub-elite hurling players. Sport Sci Health 14:201-208

2. Collins K, McRobert A, Morton JP et al (2018) The work-rate of elite hurling match-play. J Strength Cond Res 32:805-811

3. Young D, Mourot L, Beato M, Coratella G (2018) The match heart-rate and running profile of elite under 21 hurlers during competitive match-play. J Strength Cond Res 32:2925-2933

4. Beato AM, Coratella G, Schena F, Hulton AT (2017) Evaluation of the external and internal workload in female futsal players. J Biol Sport 34:227-231

5. Beato M, Impellizzeri FM, Coratella G, Schena F (2016) Quantification of energy expenditure of recreational football. J Sports Sci 34:2185-2188

6. Beato M, Coratella G, Schena F (2016) Brief review of the state of art in futsal. J Sport Med Phys Fit 56:428-432

7. Young D, Mourot L, Beato M, Coratella G (2018) Match-play demands of elite U17 hurlers during competitive matches. J Strength Cond Res. (Epub ahead of print)

8. Cullen BD, Roantree MT, McCarren AL et al (2017) Physiological profile and activity pattern of minor Gaelic football players. J Strength Cond Res 31:1811-1820

9. Reilly T, Collins K (2008) Science and the gaelic sports: gaelic football and hurling. Eur J Sport Sci 8:231-240

10. Gilmore $H(2008)$ The craft of the Caman: a notational analysis of the frequency occurrence of skills used in hurling. Int $\mathbf{J}$ Perform Anal Sport 8:68-75

11. Clear C, Hughes M, Martin D (2017) Attacking profiles in elite hurling. Int J Perform Anal Sport 17:319-333

12. Collins K, Doran DA, Reilly TP (2010) The physiological demands of hurling match-play. In: Anderson M (ed) Contemporary ergonomics and human factors. CRC Press, London, pp 591-595

13. Young D, Malone S, Beato M et al (2018) Identification of maximal running intensities during elite hurling match-play. J Strength Cond Res. https://doi.org/10.1519/JSC.0000000000 002674

14. Young D, Mourot L, Beato M, Coratella G (2018) The matchplay temporal and position-specific physical and physiological demands of senior hurlers. J Strength Cond Res 
15. Gabbett T (2012) Activity cycles of National rugby league and national youth competition matches. J Strength Cond Res $26: 1517-1523$

16. Gabbett T (2015) Activity and recovery profiles of state-of-origin and National rugby league match-play. J Strength Cond Res 29:708-715

17. Siegle M, Lames M (2012) Game interruptions in elite soccer. J Sports Sci 30:619-624

18. Augste C, Cordes O (2016) Game stoppages as a tactical means in soccer-a comparison of the FIFA world cups TM 2006 and 2014. Int J Perform Anal Sport 16:1053-1064

19. Beato M, Coratella G, Stiff A, Dello Iacono A (2018) The validity and between-unit variability of GNSS units (STATSports Apex 10 and $18 \mathrm{~Hz}$ ) for measuring distance and peak speed in team sports. Front Physiol 21:1288

20. Malone S, Hughes B, Collins K (2017) The effect of training load distribution on aerobic fitness measures in hurling players. J Strength Cond Res 1:1. https://doi.org/10.1519/JSC.0000000000 002004

21. Malone S, Collins K (2017) The influence of pitch size on running performance and physiological responses during hurling-specific small-sided games. J Strength Cond Res 31(6):1518-1524

22. Malone S, Collins KD (2017) Effect of game design, goal type, and player numbers on the physiological and physical demands of hurling-specific small-sided games. J Strength Cond Res 31:1493-1499

23. Malone S, Hughes B, Collins K, Akubat I (2018) Methods of monitoring training load and their association with changes across fitness measures in hurling players. J Strength Cond Res. https:// doi.org/10.1519/JSC.0000000000002655

24. Malone S, Hughes B, Collins K (2017) The influence of exercise to rest ratios on physical and physiological performance during hurling specific small-sided games. J Strength Cond Res 33(1):180-187. (Epub ahead of print)

25. Read DB, Jones B, Williams S et al (2018) The physical characteristics of specific phases of play during rugby union match-play. Int J Sports Physiol Perform 20:1-6. (Epub ahead of print)

26. Gabbett $\mathrm{T}$ (2015) Influence of ball in play time on the activity profiles of rugby league match play. J Strength Cond Res 29:716-721

27. Pollard BT, Turner AN, Eager R et al (2018) The ball in play demands of international rugby union. J Sci Med Sport 21(10):1090-1094. (Epub ahead of print)

28. Siegle M, Lames M (2012) Influences on frequency and duration of game stoppages during soccer. Int J Perform Anal Sport 12:101-111

29. Atencio R (1996) Eyestrain: the number one complaint of computer users. Comput Libr 16:40-44

30. Hopkins WG (2007) A spreadsheet for deriving a confidence interval, mechanistic inference and clinical inference from a $p$ value. Sportscience 11:16-20

31. Coratella G, Beato M, Schena F (2016) The specificity of the Loughborough Intermittent Shuttle Test for recreational soccer players is independent of their intermittent running ability. Res Sport Med 24:363-374

32. Beato M, Bianchi M, Coratella G et al (2018) Effects of plyometric and directional training on speed and jump performance in elite youth soccer players. J Strength Cond Res 32:289-296

Publisher's Note Springer Nature remains neutral with regard to jurisdictional claims in published maps and institutional affiliations. 